\title{
O pensamento Complexo de Edgar Morin e suas contribuições ao campo da educação: Uma análise da prática desenvolvida na Escola da Ponte à luz da Teoria da Complexidade
}

\section{Edgar Morin's Complex thinking and his contributions to the field of education: An analysis of the practice developed at Escola da Ponte in the light of Complexity Theory}

\author{
Elis Fábia Lopes CABRAL* \\ Keity Barbosa CARNEIRO** \\ Tereza Kelly Gomes CARNEIRO***
}

\begin{abstract}
RESUMO: Neste artigo buscamos tecer algumas considerações a respeito do pensamento complexo de Edgar Morin, sobretudo no que tange às suas contribuições ao campo da educação. Para tanto, foi necessário um enfoque em sua obra intitulada "Sete saberes necessários à educação do futuro", pois acreditamos que afora a vasta produção acadêmica e intelectual do autor, nesta produção Morin se esforça em estabelecer, de forma pragmática, princípios fundamentais para uma educação não fragmentada. A partir da análise dessa obra, preocupamo-nos em como a aplicação da Teoria da Complexidade se dá no campo da práxis, assim, elegemos a Escola da Ponte como um exemplo de experiência exitosa que pode servir como reflexo do pensamento de Edgar Morin.
\end{abstract}

PALAVRAS-CHAVE: Edgar Morin. Pensamento Complexo. Transdisciplinaridade. Escola da Ponte.

\begin{abstract}
In this article we seek to make some considerations about Edgar Morin's complex thinking, especially regarding his contributions to the field of education. To this end, it was necessary to focus on his work "Seven necessary knowledges for the education of the future", as we believe that apart from the vast academic and intellectual production of the author, in this production Morin strives to establish, in a pragmatic way, fundamental principles for a non-fragmented education. Based on the analysis of this work, we are concerned with how the application of the Theory of Complexity takes place in the field of praxis, thus, we chose Escola da Ponte, as an example of a successful experience that can be used as a reflection of Edgar Morin's thinking.
\end{abstract}

KEYWORDS: Edgar Morin's. Complex thinking. Transdisciplinarity. Escola da Ponte.

\section{Introdução}

Influenciado pela teoria marxista e pelo pensamento fenomenológico Hegeliano, a produção intelectual do filósofo Edgar Morin tem suas raízes intrinsecamente relacionadas à

\footnotetext{
*Mestra em Educação Profissional e Tecnológica, Instituto Federal de Educação, Ciência e Tecnologia da Bahia, ORCID: https://orcid.org/0000-0001-5194-2709, e-mail: elislopesifba@gmail.com.

** Mestranda em Educação Profissional e Tecnológica, Instituto Federal de Educação, Ciência e Tecnologia da Bahia, ORCID: https://orcid.org/0000-0003-3970-8359, e-mail: keity.bc@gmail.com.

*** Doutora pelo programa Multiinstitucional e Multidisciplinar em Difusão do Conhecimento da UFBA. Professora titular do Instituto Federal de Educação, Ciência e Tecnologia da Bahia (IFBA), ORCID https://orcid.org/0000-0002-8081-9029, e-mail: terezakelly1@gmail.com.
} 
sua militância no partido comunista francês durante a segunda grande guerra. Seu pensamento será marcado por momentos de aproximações e reinterpretações em relação ao materialismo histórico-dialético, em um primeiro momento assumindo enquanto inexorável a linearidade do processo histórico e suas fases, tal como proposta por Marx, para em seguida, apresentar outras possibilidades. Dissidente do Partido Comunista, é a partir de seu contato com as ciências modernas como a cibernética, teoria dos sistemas e a teoria da informação que a construção do Pensamento Complexo ou a Teoria da Complexidade em Morin adquire contornos que irão defini-la como uma quebra de paradigma em relação às concepções vigentes de interpretação do mundo, pautadas na compartimentalização dos saberes, sob a égide do discurso Descartiano.

Morin avança no sentido de uma transdisciplinaridade em que as barreiras entre os campos do saber estão diluídas e difusas, entrelaçando-se na tentativa de explicar o mundo e seus fenômenos através de um prisma globalizante. A exemplo de Marx, que aponta a necessidade de uma filosofia prática em constante diálogo com o mundo concreto, Edgar Morin busca desenvolver uma ciência que se quer revolucionária nos modelos de pensamento e que engendre mudanças efetivas no fazer científico e, em última instância, nos sistemas de educação.

Responsável por uma vasta obra, Edgar Morin sintetiza o seu pensamento complexo na série de seis volumes intitulada de "Métodos" publicados entre 1977 e 2004 . No escopo deste artigo, buscaremos apresentar de maneira sucinta, mas nem por isso superficial, as contribuições desse autor no que se refere ao campo educacional. Para tanto, usaremos como lastro para essa discussão a obra intitulada "Sete saberes necessários à educação do futuro", originalmente editada, em 1999, pela UNESCO e depois pela Editora Seuil, sendo traduzido para diversas línguas. Apresentaremos neste trabalho a experiência exitosa da Escola da Ponte, em Portugal, cujo projeto pedagógico reflete o Pensamento Complexo proposto por Edgar Morin.

\section{O Paradigma do Pensamento Complexo e a Questão da Educação}

A Teoria da Complexidade é pautada no pensamento de Edgar Morin, epistemólogo, expoente na estruturação desse campo de conhecimento há aproximadamente quatro décadas. Antropólogo, sociólogo e filósofo francês, Morin é autor de mais de 30 livros e considerado um dos principais pensadores contemporâneos e um dos principais teóricos da complexidade. 
A complexidade, de acordo com Morin, entende-se como o que é tecido junto (complexus), ou ainda, "efetivamente o tecido de acontecimentos, ações, interações, retroações, determinações, acasos, que constituem nosso mundo fenomênico" (MORIN, 2007, p. 13).

É exatamente na concepção do mundo fenomênico que os sujeitos devem ser entendidos como seres inacabados que se constroem ao longo da vida. Pensar a partir da complexidade humana significa se entender como seres biológicos e culturais, buscando ampliar o pensamento sobre o mundo e a vida e, junto a isso, romper com o paradigma da fragmentação dos saberes humanos, científicos e da tecnologia. Diante disso, a Teoria da Complexidade ou pensamento complexo, que será tratado aqui, está intimamente ligada às questões desenvolvidas por Edgar Morin.

O atual cenário educacional é marcado pela dificuldade de a escola cumprir sua função social no confronto com as "novas bases materiais que caracterizam a reestruturação produtiva, a economia globalizada e as tecnologias da informação e comunicação” (RODRIGUES, 2008, p. 89).

Neste sentido, uma educação voltada para a complexidade deve apresentar uma nova concepção curricular contributiva à emancipação e à autonomia capaz de religar saberes, certezas, incertezas e incompletudes, favorecendo a investigação, o questionamento, o pertencimento à condição humana inacabada, acolhendo os diferentes, valorizando o autoconhecimento e a autocompreensão, habilidades que podem contribuir para a superação da alienação e da passividade frente aos problemas da comunidade planetária.

Não se trata, portanto, de uma reformulação curricular programática, mas sim, paradigmática. Neste viés, Petraglia (2001), subsidiada pelas ideias de Morin, esclarece:

O currículo escolar é mínimo e fragmentado. Na maioria das vezes, peca tanto quantitativa como qualitativamente. Não oferece, através de suas disciplinas, a visão do todo, do curso e do conhecimento uno, nem favorece a comunicação e o diálogo entre os saberes; dito de outra forma, as disciplinas com seus programas e conteúdos não se integram ou complementam, dificultando a perspectiva de conjunto e de globalização, que favorece a aprendizagem. (2001, p. 69).

A fragmentação do saber impossibilita a ligação entre áreas, limitando e, até mesmo, dificultando a aprendizagem dos envolvidos com o processo de ensino. A reforma do pensamento exigida para a compreensão da “era planetária é pensar a sua globalidade, a relação do todo com suas partes, sua multidimensionalidade e a sua complexidade (o contexto e o global)" (MORIN, 1999, p. 64). O todo necessita das partes, assim como as partes necessitam 
do todo para que ocorra uma efetivação de ambas. Isso significa desvalorizar o avanço do pensamento disciplinar, mas não o considerar como a única via de conceber o ensino e a aprendizagem.

O desafio do século XXI é encontrar a essência do conhecimento, aprender a ler um mundo imerso na incerteza, e na perspectiva de Morin (1995), encontrar o conhecimento pertinente, aquele capaz de situar tudo no contexto, visto que a educação do futuro precisa tornar visível o contexto, o global, o multidimensional e o complexo.

Considerando esse cenário e tendo em vista o objetivo de aprofundar a visão transdisciplinar da educação, a Organização das Nações Unidas para a Educação, a Ciência e a Cultura/UNESCO solicitou a Edgar Morin que expusesse suas ideias sobre a educação do amanhã. Morin aceitou o desafio e produziu um texto intitulado "Os Sete Saberes Necessários à Educação do Futuro" publicado pela Unesco em 2000. A obra é dividida em 7 capítulos e expõe os saberes resumidos a seguir:

1. As Cegueiras do Conhecimento: Para o autor, o conhecimento está, em algum grau, ameaçado pelo erro e pela ilusão e é dever da educação mostrar que direção tomar. Mostra também o risco do erro provocado pelas perturbações aleatórias ou de ruídos, em qualquer transmissão de informação ou comunicação de mensagens.

2. Os princípios do Conhecimento Pertinente: as informações essenciais sobre o mundo devem ser contextualizadas com os conhecimentos do mundo com o mundo. $\mathrm{O}$ conhecimento para ser pertinente precisa situar as informações e os dados em seu contexto para que adquiram sentido.

3. Ensinar a condição humana: a educação do futuro deve ser centrada primordialmente na condição humana. Conhecer o humano situando-o no universo, evidenciando o elo indissolúvel entre a unidade e a diversidade, baseando-se na reunião e organização dos conhecimentos dispersos das ciências humanas e naturais, das literaturas e da filosofia. Tanto a esfera individual quanto a social devem ser compreendidas sob a égide da unidade do múltiplo e multiplicidade do uno.

4. Ensinar a identidade terrena: é indispensável indicar o complexo da era planetária, a importância da comunicação entre todos os continentes que carecem da solidariedade e discussão das opressões. A união planetária é a exigência racional mínima de um mundo 
encolhido e interdependente, mas para isso é preciso a consciência e o sentimento de pertencimento mútuo que nos une à nossa terra, considerada primeira e última pátria.

5. Enfrentar as incertezas: ensinar princípios de estratégias que permitam o enfrentamento de imprevistos, inesperados e incertezas, levando a modificação do seu desenvolvimento. O futuro permanece aberto e imprevisível, pois a história não evolui de modo linear e é por isso que a educação do futuro deve se voltar para as incertezas ligadas ao conhecimento.

6. Ensinar a compreensão: esta é o meio e o fim da comunicação humana, condição que exige a reforma das mentalidades. É válido ressaltar que a comunicação por si só não garante a compreensão, pois esta vai além da explicação: compreender inclui necessariamente, um processo de empatia, autocrítica, identificação e de projeção. A compreensão do outro requer a consciência da complexidade humana, levando à superação do egocentrismo, etnocentrismo e sociocentrismo.

7. A ética do gênero humano: a educação deve levar a "antropoética" (indivíduo sociedade - espécie), como base para ensinar a ética do futuro. Trata-se de uma missão antropológica capaz de promover o desenvolvimento humano e compreender o conjunto das autonomias individuais, das participações comunitárias e da consciência de pertencer à natureza humana. Levar a consciência da "Terra-pátria" e a vontade de realizar a cidadania terrena.

A análise dos saberes elencados por Morin para a educação do futuro, coloca-nos frente ao desafio de pensar um modelo pedagógico paradigmático com base transdisciplinar, que seja capaz de aproximar, conectar e interligar estes saberes, visando instituir um fluxo de competências e ideologias individuais que precisam ser disseminadas na coletividade.

\section{A experiência educativa da Escola da Ponte}

O educador, escritor e psicanalista, Rubem Alves (2001), ao tecer críticas ao sistema tradicional de ensino, comparando-o à lógica fabril que dita os tempos e disciplina os corpos, ressalta o quanto esses sistemas educacionais são reflexos da lógica do sistema capitalista de produção, pois reproduz a organização que busca uniformizar os sujeitos. Nas palavras de Alves: 
Nossas escolas são construídas segundo o modelo das linhas de montagem. Escolas são fábricas organizadas para a produção de unidades biopsicológicas móveis portadoras de conhecimentos e habilidades. Esses conhecimentos e habilidades são definidos exteriormente por agências governamentais a que se conferiu autoridade para isso. Os modelos estabelecidos por tais agências são obrigatórios, e têm a força de leis. Unidades bio-psicológicas móveis que, ao final do processo, não estejam de acordo com tais modelos são descartadas. (ALVES, 2001, p.36)

O autor aponta como alternativa ao modelo hegemônico de instituições escolares e ao sistema de ensino, alienante, a volta ao modelo medieval da oficina do artesão, em suas palavras "uma escola retrógrada". Neste tempo o mestre-artesão era uma espécie de orientador e os seus aprendizes estavam munidos de autonomia para escolha e execução de suas obras, o produto final do seu trabalho munia-se de identidade, pois o modelo a ser atingido era, sobretudo, um modelo projetado pelo próprio autor das obras.

Em oposição a organização escolar em que os saberes estão fragmentados em disciplinas que não dialogam entre si, Rubem Alves (2001), no seu livro intitulado "A escola que sempre sonhei sem imaginar que pudesse existir", apresenta-nos a experiência da Escola da Ponte, a qual nos remete metaforicamente ao tempo da autonomia dos aprendizes.

Fundada na década de 70, em São Tomé Negrelos, no Distrito de Porto, em Portugal, a Escola Básica da Ponte ou Escola da Ponte - Escola Básica Integrada de Aves/São Tomé de Negrelos destaca-se no cenário educacional português pelo seu projeto pedagógico singular, pautado por princípios democráticos e na oferta de uma educação inclusiva. O projeto da Escola da Ponte surgiu em 1976, liderado pelo pedagogo José Pacheco e se fundamenta na coerência entre um projeto que contém o valor "escola são pessoas" aliado a uma praxis que pressupõem a introdução de dispositivos que controlam todas as atividades. A sua estrutura organizativa é marcada pelo planejamento participativo, destacando elementos que vão desde os espaços pedagógicos ao tempo e modo de aprender.

O trabalho desenvolvido é pautado na colaboração e na auto-organização. Com uma gestão da própria e entregue à comunidade local, conta com uma assembleia de estudantes, associação de pais, uma comunidade organizada, promovendo várias ações e programas que culturalmente mantêm seu funcionamento, eliminando a função corrente de conselho diretivo escolar.

Alves (2001) faz um relato sucinto da forma como está organizada a Escola da Ponte. As descrições que se seguem partem das constatações realizadas pelo referido autor a partir de visita realizada à instituição em 2000, e foram publicadas originalmente no jornal Correio 
Popular, de Campinas, São Paulo, em formato de crônicas. Segundo este autor, diferente das escolas tradicionais, a Escola da Ponte possui uma organização singular dos seus espaços formativos. Nessa instituição não existem salas de aulas, não há separação por classes e o modelo de aula expositiva, onde o professor assume o protagonismo na condução das atividades, também é inexistente.

Na Escola da Ponte, todos os estudantes coabitam o mesmo espaço, sem divisões por classe. Em um grande espaço estão dispostos pequenos grupos de mesas e cadeiras que delimitam os grupos de trabalho. Os alunos reúnem-se por afinidade a um determinado assunto de interesse, a eles são passadas instruções de pesquisa por um professor tutor que os acompanhará periodicamente. A aprendizagem e o ensino se dão de forma comunitária, as crianças que possuem certo nível de conhecimento estão imbuídas da atribuição de ensinar as crianças que não sabem. As crianças com necessidades específicas também estão integradas às atividades com as outras crianças, pois se parte do pressuposto de que todas as crianças possuem necessidades diferenciadas. Aos moldes republicanos, as crianças são as responsáveis por estabelecer as regras de convivência e discutir os problemas da escola, para isso constituem os fóruns coletivos compostos por estudantes eleitos pelo grupo.

Atualmente, inserida no sistema público de ensino português, a experiência inovadora da Escola da Ponte tardou a ser reconhecida pelo Ministério da Educação, apesar da excelência comprovada por todas as inspeções e estudos, mesmo a nível mundial. Hoje, a instituição é uma referência de um modelo de ensino que tem como centro a cidadania, a autonomia dos estudantes e a auto-organização.

\subsection{Concepções do Projeto Educativo}

Embora não seja uma experiência expressamente baseada na teoria da complexidade, a Escola da Ponte possui inspirações alinhadas ao pensamento de Edgar Morin. O seu Projeto Educativo - documento basilar que carrega o DNA da instituição, equivalente ao Projeto Político Pedagógico das escolas brasileiras - traz em seu corpo a referência às teorias construtivistas, especialmente nas suas metodologias centradas no estudante. No entanto, são evidentes as inspirações oriundas da complexidade, como é possível perceber nos trechos expostos nos parágrafos a seguir.

Logo no início do projeto são expostos os princípios fundamentais que balizam a ação da escola, destacando-se que a união de todos os atores educacionais é indispensável à execução 
da proposta educativa, bem como o fato de que todos devem conhecê-la e assumi-la. Toda a orientação pedagógica destina-se à formação humana e integral, valorizando a construção de importantes elementos individuais como autonomia e responsabilidade, sem descuidar daqueles ligados à vida em sociedade como valorização da cultura, solidariedade, democracia e compromisso com uma nova ideia de sociedade.

Ainda sobre a preocupação com o coletivo, é imprescindível dizer que os pais e mães dos estudantes são muito valorizados na estrutura escolar. O Regimento Interno, outro documento norteador da escola, traz a alocação dos responsáveis em Conselhos com alto poder de decisão e, até mesmo, acima da Gestão. Compreende-se que a instituição propõe uma prática educativa, mas esta precisa ser referenciada e adequada aos anseios dos estudantes, responsáveis e da sociedade como um todo.

A intencionalidade educativa do Projeto fica bem definida e expressa a visão que deve permear quaisquer práticas no âmbito da instituição, sejam elas ligadas à gestão, administração, pedagógicas ou humanas. Além disso, é ressaltada a diferença da proposta em relação às demais escolas ao trazer uma crítica sobre a forma como as demais estruturam-se:

A Escola não é uma mera soma de parceiros hierarquicamente justapostos, recursos quase sempre precários e atividades ritualizadas - é uma formação social em interação com o meio envolvente e outras formações sociais, em que permanentemente convergem processos de mudança desejada e refletida. (PORTUGAL, [s.d.], p. 2).

Sobre o currículo, fica estabelecido que ele é centrado no aluno, porém, tal princípio não é aplicado apenas na metodologia, mas também na definição do que vai ser estudado. $O$ Projeto Educativo vê cada estudante como ser único e portador de uma experiência exclusiva e, por tal motivo, o currículo também precisa seguir caminhos individualizados, embora sempre na perspectiva dos valores já trazidos anteriormente como iniciativa, criatividade e responsabilidade.

Há uma expressão que merece destaque pelo enorme significado que carrega: "todo o aluno tem necessidades educativas especiais". A princípio, poderia soar-nos estranho, dado ao hábito do senso comum de associar necessidades específicas e pessoas com deficiência à ausência de algumas capacidades. No entanto, a expressão é utilizada para ratificar que cada estudante possui a sua forma de aprendizagem e ela precisa ser compreendida, respeitada e estimulada. Na Escola da Ponte, cada estudante possui o tutor que lhe acompanha e, dentre outras atribuições, ele zela pelos registros do processo avaliativo no dossiê individual. 
Retomando o conceito de currículo, ele é compreendido como uma trajetória a ser percorrida pelo estudante, contemplando algumas competências necessárias para atingir os princípios definidos pelo Projeto Educativo, sendo que tal percurso é muito vinculado às apropriações subjetivas que os estudantes fazem dele. Nas palavras do próprio Projeto:

O conceito de currículo é entendido numa dupla asserção, conforme a sua exterioridade ou interioridade relativamente a cada aluno: o currículo exterior ou objetivo é um perfil, um horizonte de realização, uma meta; o currículo interior ou subjetivo é um percurso (único) de desenvolvimento pessoal, um caminho, um trajeto. Só o currículo subjetivo (o conjunto de aquisições de cada aluno) está em condições de validar a pertinência do currículo objetivo. (PORTUGAL, [s.d.], p. 3)

O fato de estar vinculado às apreensões individuais não torna o currículo disforme e aleatório; além de pautar-se nos princípios, como já dito anteriormente. O currículo exterior segue uma estrutura básica vinculada ao currículo nacional, possuindo dimensões préestabelecidas: linguística, lógico-matemática, naturalista, identitária e artística, pessoal e social. Além destas, também são contempladas e valorizadas as dimensões que trabalham o desenvolvimento afetivo e o emocional, com vistas a contemplar as atitudes esperadas dos estudantes no campo ético e relacional. A plataforma curricular é a mesma para todos os estudantes, mas desenvolvida de forma única, individualmente, de forma a adaptar o ensino dos conteúdos às formas de aprender de cada um deles.

A construção do conhecimento parte da experiência que os estudantes vivenciam e que, a partir dela, constroem significados. Não cabem neste contexto as práticas que compartimentam os saberes e transformam-nos em repetição mecânica e descontextualizadas. Pela compreensão do conhecimento fragmentado em disciplinas como incipiente para o perfil pretendido, as aprendizagens significativas ocorrem sempre a partir da interdisciplinaridade, estimuladas pela resolução de problemas e o pensar crítico, desafiando o intelecto a elaborar estruturas de pensamento cada vez mais complexas.

Para efetivação do currículo é utilizada a metodologia de projetos, o que confere dinamicidade ao currículo objetivo e necessidade constante de (auto)avaliação, de forma que os orientadores educativos possam planejar com o cuidado necessário os recursos e materiais pedagógicos mais adequados. Todo o percurso de aprendizagem é registrado e utilizado como matéria-prima para sua avaliação, constituindo um documento que comunica ao estudante e aos seus responsáveis a evolução do processo, bem como será utilizado para fazer as transições entre os núcleos de projeto - conceito que transmite a ideia de passagens de nível dentro da 
trajetória escolar; poderia ser comparado à seriação que utilizamos no Brasil, mas os núcleos de projeto carregam uma concepção muito mais flexível e mais vinculada a princípios do que as faixas etárias.

O ensino compreende que os alunos estão expostos a diversos ambientes educativos, em espaços formais ou não, e que as aprendizagens não são integralmente controladas pela escola. Cabe à instituição diversificar também as experiências que proporciona, bem como avaliar constantemente os processos desenvolvidos, demonstrando aos estudantes quais são os avanços já alcançados e quais são aqueles ainda almejados. De acordo com o Projeto:

Acompanhar o percurso do aluno na construção do seu projeto de vida, tendo consciência da singularidade que lhe é inerente, impõe uma gestão individualizada do seu percurso de aprendizagem. A diversidade de percursos possíveis deverá, no entanto, acautelar o desenvolvimento sustentado do raciocínio lógico matemático e das competências de leitura, interpretação, expressão e comunicação, nas suas diversas vertentes, assim como a progressiva consolidação de todas as atitudes que consubstanciam o perfil do indivíduo desenhado e ambicionado neste Projeto Educativo. (PORTUGAL, [s.d.], p. 4)

O acompanhamento dos estudantes é realizado pelos orientadores educativos profissionais que vão além da designação de professor costumeiramente atribuída, pois não assumem a ideia de porta de acesso dos alunos a um conhecimento pré-determinado. $\mathrm{O}$ orientador educativo é responsável por executar os princípios trazidos pelo projeto e a orientar processos de cada estudante, acompanhando sua aprendizagem e identificando as dificuldades. E, reconhecendo tais dificuldades, os orientadores devem ser capazes de superá-las, inclusive percebendo quando elas estão mais vinculadas ao ensino que à aprendizagem. Além disso, os educadores também assumem o papel de tutor, que é o elo entre a instituição e o responsável pelo estudante (encarregado de educação). Como a formação é um elemento essencial para desenvolver todas as atribuições de um educador, compreende-se que sua formação deve acontecer em contexto de trabalho, até mesmo a inicial, recorrendo a outras instituições sempre que for necessário.

\section{Análise da Proposta à Luz da Teoria da Complexidade}

Seguindo o viés da epistemologia da complexidade é possível fazer a análise dos discursos pedagógicos da Escola da Ponte, tendo como foco o princípio da reestruturação pedagógica e institucional necessária na pós-modernidade, superando assim, o modelo 
tradicional de ensino através da mudança paradigmática da ciência moderna para o paradigma da complexidade, muito marcante em todo escopo da proposta.

A experiência educativa, desenvolvida na Escola da Ponte, constitui a mais clara afirmação do que pode ser a construção da autonomia de uma escola, baseada no compromisso com a construção de uma escola de todos e sustentada pelo investimento na democratização e participação da comunidade em seus processos de gestão. O projeto tem como princípios quatro ideias, que funcionam com uma espécie de matéria-prima para o trabalho pedagógico: autonomia, responsabilidade, solidariedade e democracia, que abrigam outros, igualmente importantes, como a liberdade, o respeito, a justiça, a verdade, a afetividade, a cooperação.

Os valores subjacentes a esses princípios apresentam sintonia com o que Morin (2000) denomina de "bases para ensinar a ética do futuro" - A antropoética, de acordo com o autor. diz respeito à ética propriamente humana que emerge da consciência da trindade indivíduo/espécie/sociedade e nos instrui a assumir a missão antropológica de desenvolver: a ética da solidariedade, a ética da compreensão, o respeito ao outro quanto às suas diferenças e identidade. A antropoética inspira a humanização da humanidade, desenvolvendo no sujeito a consciência e cidadania planetária.

A superação dos modelos hegemônicos de organização da escola e dos processos de ensino e aprendizagem, tais como: turma, série, ano, ciclos, aula direta ou expositiva, salas isoladas, monodocência, sinalizam a reforma paradigmática que busca romper com a ideia do ensino baseado em saberes compartimentados e que tornam invisíveis o contexto, o global, o multidimensional e o complexo. De acordo com Morin (2000, p. 35) “a era planetária necessita situar tudo no contexto e no complexo planetário. O conhecimento do mundo como mundo é necessidade ao mesmo tempo intelectual e vital".

O princípio da autonomia é revelado a todo tempo na proposta, como sendo o contrário de dependência e servidão, uma vez que é canalizador de um eixo em que os interesses individuais e coletivos se fundem, em prol do bem comum. Portanto, nem as normas de conduta da instituição podem ser construídas à margem da participação e corresponsabilização de todos, tampouco o que deseja uma única pessoa poderá prevalecer para todos. Esse modelo pedagógico defende a ideia de que só há autonomia com os outros. Não há uma autonomia plenamente individual.

Neste sentido, Morin (1996) defende que a autonomia está estreitamente ligada à noção de dependência do meio ambiente, e não às antigas concepções de liberdade. Todavia, conforme 
tal pensamento, a autonomia não seria somente a capacidade de livre escolha, mas a capacidade de estar em conformidade com a organização do meio ambiente em que este ser se encontra inserido. Em outras palavras, um sujeito autônomo no mundo precisa ser capaz de se perceber no "todo complexo" em que está inserido.

A ideia de responsabilidade presente na proposta está relacionada à cidadania, pois esta é tributária de pessoas autônomas e, consequentemente, responsáveis. A responsabilidade surge como um valor que respalda o compromisso de todos com uma obra comum. Os compromissos são assumidos pelo sentimento de pertencimento e implicação com as ações individuais e coletivas.

A solidariedade, na concepção pontista, não é peça de retórica e tampouco a incorporação de um jargão esvaziado da vivência na prática. Integra um quadro de valores convergentes à ideia da antropo-ética. A solidariedade vivenciada na escola, no sentido aqui compreendido/defendido pelos idealizadores dessa concepção, expressa a comunhão de atitudes de cada um com o outro e com todos, formando uma unidade que favorece às aprendizagens, às situações de formação, de gestão coletiva, de diálogo e resistência às pressões externas.

Por último, trataremos da democracia que no projeto se expressa a partir da partilha do poder, da descentralização da autoridade, da liberdade para a defesa de posicionamentos originários de uma pessoa, de um grupo minoritário ou mesmo da maioria. Nessa perspectiva, Morin (2000, p. 108) faz uma afirmativa: "a democracia supõe e nutre a diversidade dos interesses, assim como a diversidade de ideias. O respeito à diversidade significa que a democracia não pode ser identificada com a ditadura da maioria sobre as minorias”.

Cabe destacar que embora a proposta educativa da Escola da Ponte seja um referencial na ruptura dos métodos pedagógicos tradicionais, há algumas críticas muito mais relacionadas às condições do projeto do que ao projeto propriamente dito.

Alguns críticos desqualificam a proposta sob o argumento de que é muito fácil fazer uma revolução pedagógica com um número reduzido de estudantes matriculados. Vejam que é uma crítica às condições, mas sem especificamente analisar o projeto. Há também alguns educadores portugueses que chamam a atenção para o perigo de reduzir o sucesso educacional em apenas um horizonte ou uma única experiência. Um deles em um artigo intitulado "Há mais vida para além da Escola da Ponte”, apresentando a seguinte reflexão: 
(...) gostaria de dizer, em primeiro lugar e sem qualquer ambiguidade, que sou favorável a qualquer projeto inovador, sobretudo quando ele reúne condições de durabilidade e quando, junto a educadores, educandos e cidadãos em geral, vai ganhando credibilidade científica, pedagógica e democrática. Já me custa mais a aceitar que em Portugal e, em grande medida, graças à crescente visibilidade social de um projecto como o da Escola da Ponte (a que não será estranha uma eficaz gestão simbólica, certamente fundada na capacidade de mobilizar a comunicação social e outros legítimos recursos de poder/saber, persuasão ou mesmo de marketing, pouco acessíveis, aliás, à generalidade dos cidadãos) possamos ser induzidos a pensar (ainda que não intencionalmente) que a realidade das nossas escolas, toda ela, está muito aquém das "boas" realizações (ou, pelo menos, de algumas das "boas" realizações) atribuídas e atribuíveis ao projecto da Escola da Ponte, e que, por isso mesmo, este caso é "a excepção que confirma a regra". (AFONSO, p.1, 2004)

No Brasil, por vezes, experienciamos o modismo de métodos pedagógicos, o que leva alguns educadores alertarem quanto ao risco de deslumbramento. Neste sentido, Vasconcellos (2016, p. 09) afirma que:

Não se trata, evidentemente, de negar as várias contribuições teóricas (aliás, José Pacheco costuma dizer que o método da Ponte é eclético, que tem influência de muitas contribuições teóricas), mas de articulá-las em torno de um projeto, e não ficar pulando de uma para outra a cada novidade. Será que precisamos de uma nova relação de idéias sobre a realidade ou nova relação com as idéias e com a realidade?

Mais uma vez a reflexão não atinge o projeto, mas o modo como ele pode ser aplicado ou os efeitos que pode causar. É bem verdade que existem muitas propostas pedagógicas inovadoras, entretanto a proposta da Escola da Ponte destaca-se por ser uma experiência que conseguiu sair do papel e resultar em práticas muito alinhadas com o objetivo de concepção do projeto.

A análise da concepção de ensino e a aprendizagem presente na proposta da Escola da Ponte nos convida a romper com a lógica da fragmentação, hiperespecialização e redução do saber. É possível perceber na proposta o desafio do pensamento complexo, que é tratar o todo de forma indissociável, tendo como desejo a construção do conhecimento a abordagem multi e transdisciplinar como eixos basilares para o rompimento da visão do pensamento simplificador e reducionista.

\section{Considerações Finais}

Embora ainda distante de tornar-se um pensamento hegemônico, os pressupostos teóricos apresentados pelo pensador Edgar Morin, com a Teoria da Complexidade, apontam 
para a necessidade da construção de um pensamento globalizante, em que a quebra com o paradigma vigente, marcado pela segregação dos saberes, é um imperativo. Talvez ainda sejam necessárias algumas décadas para que a "revolução do pensamento", proposta por Morin, se efetive. Considerada por alguns filósofos como utópica, dado o estado da arte do conhecimento científico, a transdisciplinaridade encontra eco, embora ainda incipiente, em experiências como a idealizada por José Pacheco, ainda na década de 70 do século passado, com a Escola da Ponte.

No presente estudo, buscamos apresentar alguns pontos de intersecção entre a experiência dessa instituição pública portuguesa e o pensamento de Edgar Morin, sem almejar encontrar uma experiência acabada da aplicação deste pensamento, outrossim, buscando colocá-la no campo das possibilidades, haja vista seu lugar de referência no cenário mundial.

É perceptível ao longo de todo o artigo como as propostas estão pautadas em princípios muito similares, especialmente na visão da educação como um tecido de constituintes diversas, heterogêneas, mas que não podem ser compreendidas de forma isolada. Assim, entendemos que o processo de ensino-aprendizagem na Escola da Ponte pauta-se no duplo movimento entre o individual e o coletivo, não de formas sobrepostas, mas em constante interação e modificação de um pelo outro - numa clara associação com a definição de Morin sobre a complexidade.

Contudo, considerando que os dados para a produção desse artigo foram obtidos através de fontes secundárias, ressaltamos a necessidade da realização de outras pesquisas que explorem de forma mais profunda, a exemplo de estudos in loco, às práticas pedagógicas que são desenvolvidas na instituição em tela. A análise de tais associações pode quebrar resistências à aplicação da teoria da complexidade na educação, tendo em vista a possibilidade de demonstrar que é viável e exequível pensar numa outra forma de educação para uma nova forma de sociedade, que exige dos educadores e educandos uma postura de autonomia, solidariedade, cooperação e respeito a todas as formas de vida presentes na Terra Pátria.

\section{Referências Bibliográficas}

AFONSO, A. J. Há mais vida para além da Escola da Ponte. A Página da Educação, Porto, n. 134, Maio 2004. Disponível em: https://www.apagina.pt/?aba=7\&cat=134\&doc=10098\&mid=2. Acesso em: 19 ago. 2021.

ALVES, R. A escola com que sempre sonhei sem imaginar que pudesse existir. 10 ed. São Paulo: Papirus Editora, 2001.

MORIN, E. A noção de sujeito. In: D. F. Schnitman (Org.), Novos paradigmas, cultura e subjetividade. Porto Alegre: Artes Médicas, 1996, p. 45-55. 
MORIN, E. Os sete saberes necessários à educação do futuro. Tradução de Catarian Eleonora F. da Silva e Jeanne Sawaya. São Paulo, Brasília, DF: Cortez/UNESCO, 1999.

MORIN, E. Introdução ao pensamento complexo. 3. ed. Porto Alegre: Sulina, 2007.

PeTRAglia, I. C.A Educação e a Complexidade do Ser e do Saber. $5^{\text {a }}$ ed. Petrópolis: Vozes, 2001.

PORTUGAL. Escola da Ponte. Projeto Educativo. [s.d]. Disponível em: http://www.escoladaponte.pt/novo/projetos/. Acesso em: 05 mai. 2020.

PORTUGAL. Escola da Ponte. Regulamento Interno. [s.d]. Disponível em: http://www.escoladaponte.pt/novo/projetos/. Acesso em: 05 mai. 2020.

RODRIGUES, Z. A. L. Paradigma da ciência, do saber e do conhecimento e a educação para a complexidade: pressupostos e possibilidades para a formação docente. Revista Educar, Curitiba, n. 32, p. 87-102, 2008, Jun. 2008. Disponível em: https://www.scielo.br/j/er/a/DSgfXSh4yCv6yprj4Bvp9ts/abstract/?lang=pt. Acesso em: $01 \mathrm{de}$ ago. 2021.

VASCONCELLOS, C.dos S. Reflexões sobre a Escola da Ponte. Revista de Educação, AEC, n. $141 \quad$ out./dez.2006. Disponível em: https://www.passeidireto.com/arquivo/44690714/reflexoes-sobre-a-escola-da-ponte/4. Acesso: 19 ago. 2021. 